\title{
Sobre la novela rapsódica y la urbe
}

$F^{N}$ general la novela iberoamericana está más cerca del desarro-

llo de las otras artes modernas - pintura, escultura, músicaque lo está la de Europa. Los pintores, al generalizarse la fotografía se apartaron de la pintura anecdótica y representativa y a partir de Cezanne comenzaron a desviarse hacia la imaginación pura. Es raro que la novela no haya hecho en Europa otro tanto en relación con el realismo naturalista. No hay todavía en Europa escritores equivalentes a Cézanne, Gaugin, Modigliani, Picasso, Matisse, Miró, etc. Huyendo del naturalismo algunos novelistas iberoamericanos parecen acercarse más a las formas equivalentes de lo que acordamos llamar la nueva sensibilidad.

La verdad es que lo que el novelista europeo de masas obtiene hoy se puede hacer mejor con la fotografía en blanco y negro (realismo clásico) o en colores (naturalismo) del cinema. Sin embargo, siguen adheridos al realismo naturalista la mayor parte de los escritores, incluso los más modernos y en apariencia discrepantes como Sartre, Aymé y hasta el increíble y difícil de aludir por el inmenso escándalo moral que lleva consigo: Geret.

En América del Norte el caso es el mismo, agravado por la recompensa desproporcionada que el novelista obtiene si sigue fiel a los patrones del conformismo y a las normas - tan venerables ya en edad y merecimientos-- de las escuelas de Balzac y Zola. La pintura en cambio, lo mismo que en Europa, ha encontrado aquí nuevas formas. No hay que olvidar que la pintura puede afrontar mejor la aventura porque es menos responsable, socialmente hablando. Sus don de contagio es menor y sólo en un nivel sensual: volúmenes y líneas. La novela es suasoria y lleva en su persuasión una opinión 
del mundo. Su originalidad es peligrosa. Muchos buenos burgueses americanos tienen en su casa copias del autorretrato de Van Gogh donde el pintor aparece con la cabeza vendada. Una novela sobre el pintor holandés tendría que explicar que la venda la tiene porque Van Gogh se ha cortado una oreja. En el análisis de su locura tendrían que citarse algunos hechos estupendos, como el de haber llevado la oreja cortada a un burdel, e intervenir también elementos religiosos porque el espiritualismo místico jugaba un papel importante en los desórdenes del artista. El libro resultaría escandaloso.

El cinema añade a la fotografía una dimensión por la cual toma la peligrosidad de la novela. Por esa razón, lo primero que hacen al planear un film es expurgar del escenario todas las trazas de originalidad. La originalidad es discrepancia, es decir, escándalo, como en la versión literaria del retrato de Van Gogh. El cinema evita la originalidad porque no es un arte sino una industria y artificio: Las responsabilidades sociales del cinema son las mismas de la novela realista y naturalista con una añadidura: la intensidad y universalidad de un género que entra por los ojos. Lo mismo que el cinema la novela naturalista en América es una industria y se puede considerar también como un arte aplicado.

Esto lo comprendemos todos. Lo que es más difícil de comprender, como decimos antes, es que la novela naturalista persista cuando el cinema es mucho más eficiente en ese campo. La novela tendría otros horizontes que descubrir y caminos que andar. $\mathrm{La}$ novela tiene muchas más posibilidades que el cinema por dirigirse a los lectores, de uno en uno. El cinema se dirige a una asamblea y el pudor colectivo es mucho más sensible que el del individuo.

En cambio, el teatro, con la dificultad también de un auditorio - de una colectividad - ha ido más lejos que la novela. Los grandes éxitos teatrales de los últimos cuarenta años en América no han sido con comedias realistas ni naturalistas (eso lo dejan al cinema) sino con obras de un desarrollo fantástico y de intención exclusivamente lírica: Crommelink, Lenormand, Camus, Capek, Molnar. No ha ido el teatro tan lejos como la pintura pero al menos parece haber hallado el camino.

Lecturas recientes me han llevado a observar una vez más que la crisis del naturalismo en la novela ha comenzado a pesar de todo y que esa crisis es más visible y evidente en los países iberoamerica- 
nos que en Europa o en Norteamérica. El único país donde se cultiva todavía con entusiasmo y con éxito es América del Norte y las razones son, como se puede deducir, de un orden que excede la discusión puramente literaria para entrar en otro mundo muy diferente: el de la industria editorial. La mayor parte de los que cultivan la forma realista y naturalista con su análisis psicológico moral, sus sorpresas escalonadas, su dosis de sexualidad brutal o idealizada, sólo existen como proveedores de materia prima industrial. (Contando no sólo con el cinema, sino con la televisión, la publicación en series o entregas, la dramatización, etc.) No hace mucho estuve con uno de esos escritores americanios que son más bien magnates del comercio librero. Ha alcanzado ese colega uno de los primeros lugares de la literatura dentro y fuera de América. Es un caso curioso. Viaja acompañado de un estado mayor impresionante: agente de publicidad, agente financiero, agente cinematográfico y un par de secretarios. Cuándo imaginamos a Unamuno o a Valéry o Güiraldes o el argentino Jorge Luis Borges con esa caterva de expertos y prácticos sentimos la ofensa de lo incongruente. Sin embargo, como digo, ese escritor en quien no hay más remedio que admirar la intuición psicológica y el don organizador de sus materiales en los planos emocionales sensual y afectivo representa hoy, con dos o tres más, la literatura americana. La verdad es que no da la impresión de alguien que vive de las nobles tareas de la imaginación sino de un hombre de negocios, próspero. $\mathrm{Ni}$ en Francia ni en los países americanos de habla española serían posibles esos casos aunque hubiera un mercado como lo hay aquí. Pero, además, en Suramérica los novelistas se apartan más cada día del realismo naturalista.

No es extraño. Esa corriente lleva más de setenta años de existencia y sólo entre las masas semieducadas literariamente puede of recer aun verdadero interés. La existencia de esas masas es dudosa en la América de habla española con excepción tal vez de la Argentina. Esas masas serían en México, Chile, Perú, Centroanérica los indios y los mestizos que siguen sin incorporarse a la llamada civilización. ¿Qué interés pueden tener para ellos los problemas de la novela naturalista francesa o española? ¿Se concibe a un indio de Xochimilco por muy incorporado que esté a la ciudad leyendo una traducción española de Emilio Zola, un libro de la Pardo Bazán o 
unà novela chinoide de Pearl Buck? La sociedad literaria iberoamericana está formada de minorías que escriben para minorías.

Las masas iberoamericanas están atrasadas en relación con las de América mientras que las minorías de habla española son tan evolucionadas y avanzadas - y quizá más- que las de este país. Al hablar de esas minorías me refiero a los novelistas y poetas. Porque en la crítica la élite americana es, en general, más apta y alerta y tiene un gusto más depurado, al menos en mi modesto parecer. Lo malo de la crítica americana es que no tiene influencia alguna sobre las masas y que sirve sólo de consolación y retribución moral para tal cual escritor no comercial.

En realidad la novela -naturalista o no- es el último género que aparece en la historia de las culturas y se da en la América de habla española de un modo esporádico e irregular. No alcanza la popularidad obtenida a menudo por la poesía. Tal vez por vivir los pueblos iberoamericanos en un periodo de formación - de cristalización de patrones culturales propios- y tener en estado latente sus caracteres definitivos, esta época debía ser aún la de la crónica histórica y de la poesía. En las dos, sobre todo en la poesía, la cultura iberoamericana es rica. Con más o menos influencia francesa o española desde mucho antes de Rubén Darío hay un acento poético que da la tierra virgen y que hace que incluso poetas tan castellanos como Sor Juana Inés de la Cruz ofrezcan en el siglo xvir, mucho antes de existir los simbolistas o los parnasianos, un acento lírico más rico de resonancias (sobre todo en lo senstal-onírico) que en Castilla y en Francia. Pero si la poesía es natural en los países ibercamericanos y se produce a menudo de un modo espontáneo como en el niño cuando prueba a juntar palabras o en los albores de las nuevas culturas - Provenza, Galicia y Cataluña en la Edad Media- la novela tal como hoy se entiende en América, Inglaterra o Francia no tiene aún sus hombres. ( $O$ no los tiene ya). Y no es extraño. El análisis psicológico de los franceses, la agudeza interpretativa de los ingleses, son virtudes de decadencia. En cuanto a la influencia española más reciente ¿qué pueden enseñar novelistas como Baroja, Unamuno o Pérez de Ayala? El primero un realismo fotográfico que obtiene tal vez algún efecto por depresión, melancolía y desencanto de viejo europeo. (Nada más viejo que las novelas juveniles de Baroja.) Unamuno en la novela no hizo cosa que me- 
rezca ser leída fuera de Nada menos que todo un hombre cuyas virtudes son las de una escuela ya declinante en la que fueron maestros Clarín, Galdós, Pereda y el portugués universal Eça de Queiros. Cuando tratamos de leer ahora Niebla, Paz en la Guerra y otras narraciones de Unamuno nos avergüenza un poco el prestigio que ese escritor tuvo en Iberoamérica y tenemos que recordar que ese prestigio lo mereció más bien con sus ensayos, a menudo luminosos. En cuanto a Pérez de Ayala sus novelas están hechas con una preocupación -es decir, una idea moral preconcebida - que lucha como puede con el barroquismo de una prosa artificial cuyo artificio, demasiado fácil, fatiga. Poca podía ser la influencia de esos novelistas en un continente virgen cuyas minorías creadoras -es decir, de imaginación y fantasía originales- puestas a buscar influencias podían hallarlas en novelistas más substanciosos y cualificados. Los románticos rusos, por ejemplo. O los ingleses del siglo XIX.

La novela iberoamericana no sólo existe a pesar de todo, sino que tenemos a mano ejemplos de una enorme dignidad. Lo que pasa es que en general rebasan el realismo naturalista europeo o americano y lo usan sólo como un medio para obtener fines de otra naturaleza: fines rapsódicos. Esta es, sin duda, una inclinación natural a la circunstancia lírica en la que toda la vida literaria iberoamericana están aún inmersa. A mí me parece mejor, en general, la novela rapsódica iberoamericana que las narraciones de Mauriac, Gide, Malraux y recuerdo con nostalgia los días en que podía permitirme el lujo de leer Don Segundo Sombra de Güiraldes tumbado en un diván, suspendido el tiempo y sus cuitas para abandonarme al ejercicio dulcemente fatigador de desintegrarme y reconstruirme entero en otro mundo. Lo mismo me sucedía con Doña Bárbara, de Gallegos. Las dos novelas usan del realismo naturalista para obtener ese plano nebuloso en el que lo inefable -igual que en la poesía lírica- es el valor determinante. En Don Segundo Sombra se obtiene con efectos descriptivos y estáticos. En Doña Bárbara predomina lo narrativo. Las dos of recen un nivel difuso superior al de los hechos y los caracteres en el que se va fraguando la atmósfera de la emoción. Esa atmósfra dificultá a menudo el paso a la luz de cada día -la de los naturalistas- pero produce la luz zodiacal o la de las tormentas. De las tormentas donde con- 
tienden lo sensual y lo intelectual, lo afectivo y lo espiritual, sin darnos a los lectores solución ni sintesis (como hacen los naturalistas) sino sugestiones para seguir adelante por un camino rico en estímulos interiores. ¿Estímulos para qué? Una vez más la obra de arte nos confronta con las contradicciones fecundas de la misma creación natural: estímulos para la quietud y la contemplación. Esa actitud, la más llena de sentido quizá, que es no hacer nada y que nos permite vernos a nosotros mismos en las dimensiones que los demás no podrían nunca percibir.

Estoy seguro de que ninguna de esas dos novelas suramericanas traducidas al inglés ha tenido muchos lectores aunque no les haya faltado el elogio de los críticos. Aquí, la novela se escribe para las masas y a veces esas novelas son excelentes dentro del patrón general, pero su falta de estímulos vanos - porque deliciosamente vanos son los estímulos a la inercia réflexiva- va acompañada de un poder y aptitud contrarios: nos estimulan a la acción exterior o al combate con nosotros mismos. Si no nos conducen a una actitud social, política o religiosa al menos iluminan problemas que nos obligan a cambiar de opinión sobre los hechos generales o a hacernos una opinión nueva. Esto sucedía también en el siglo pasado con Balzac, Stendhal, Hugo. Por no rebasar casi nunca esos niveles del mundo de los fenómenos positivos la mayor parte de las novelas americanas resultan mejores en el cinema que es la más convincente de las formas que ha tomado por hoy el realismo naturalista. A nadie le extrañarán estas opiniones si se recuerda lo que los italianos han obtenido en films como "El ladrón de bicicletas", "Los limpiabotas" o "Ciudad abierta". ¿Es que la novela naturalista puede ir más lejos? Yo dudo de que ningún novelista de esa escuela pueda obtener la riqueza de matices psicológicos de esos films con la misma economía de medios expresivos (en el espacio de dos horas que dura el espectáculo) y sin forma alguna de afectación $\mathrm{y}$ menos de afectación retórica. Por no haber en " $\mathrm{El}$ ladrón de bicicletas" casi no hay palabras.

No hay en América del Norte novelas naturalistas tan expresivas. Tampoco hay escritores experimentales -es decir, que escriban para escritores - tan unánimemente aceptados como los de nuestro mundo iberoamericano. La literatura yanqui no tiene personalidades de un prestigio nacional y menos continental basadas en 
obras narrativas neutras puras y $\sin$ implicaciones sociales positivas. Estoy pensando en un librito de fantasía e imaginación cuya acción es indeterminable o poco menos: en $\mathrm{El}$ hombre que parecía un caballo, de Arévalo Martínez. Por otra parte es en Guatemala, nación joven $\mathrm{y}$ sin mercados literarios - con masas no incorporadas- donde se escribió y publicó ese libro que tiene la sutileza de algunas prosas de Valéry y más frescura y espontaneidad. Este hecho debe extrañar a los americanos que creen que sin una industria literaria del libro - como hay en París o en New York- no puede existir la literatura.

Hace poco discutía yo de esas materias con dos editores de $\mathrm{New}$ York. Les recomendaba el libro recientemente publicado del escritor chileno Manuel Rojas Hijo de ladrón, del que conocían un extracto y me decían que los escritores argentinos y chilenos en general dan la impresión de una tremenda desorientación interior. Yo les decía que es mejor estar desorientado pero en trance receptivo que mal orientado. Ellos querían demostrarme que sólo en paises con grandes revistas literarias y verdadera organización editorial los escritores y las masas saben lo que quieren. Más o menos pérfidamente pero con una base de verosimilitud les decía yo que la imprenta y las casas editoriales han hecho mucho daño a la literatura y que desde que existe la imprenta no se han escrito obras tan importantes como La Divina Comedia de Dante o la Eneida de Virgilio o las Vidas Paralelas de Plutarco o los diálogos de Platón. En los dos siglos siguientes a Gutenberg cuando no existían todavía revistas ni críticas ni casas editoras se escribieron La Celestina, Don Quijote, El Paraíso Perdido y otros libros del mismo nivel. En nuestros días el libro que más ha agitado la atmósfera, Ulyses, se publicó en inglés fuera del mundo británico, en una librería de París, casi clandestinamente.

A uno de esos editores le había propuesto el año pasado la traducción y publicación de Juan de Mairena de Machado. Leyó algunas páginas y dijo: "Este autor está lleno de contradicciones". Repliqué yo que no eran sino oposiciones deliberadas de términos - la duda dialéctica- y que la insistencia en la contradicción era en todo caso una secuencia lógica. "No, no. Aunque así sea resulta confuso y. un libro confuso no se vende", decía él. Le recordé que el libro literariamente más confuso de la historia de la humanidad había 
sido y era todavía el primer best seller: la Biblia. El editor respondió con un silencio ambiguo y un gesto que parecía decir: "Con estos guys latinos no se puede". En fin, no quisieron imprimir a Antonio Machado. Ni lo imprimirán mientras sea la pujante creciente y acaudalada industria editorial quien decida.

Hay libros iberoamericanos que se acercan más al realismo naturalista que invade estos prósperos mercados. Por ejemplo, Los de Abajo, de Azuela y La Vorágine, de Rivera. En los dos hay un repertorio de acentos y tonos que fueron eficaces después de la primera guerra mundial y además en La Vorágine hay una tendencia monumentalista tentadora para las casas editoriales. Pero no es fácil engañarles. Es decir, no es fácil darles una moneda de oro por una de cobre. Sería un engaño ventajoso de cuyo provecho recelan. Suponen que Los de Abajo es peor que un libro rapsódico y lírico porque es además un libro inconformista. Se pueden publicar libros inconformistas con la condición de que sean tan escandalosos que resulte imposible ignorarlos. $Y$ todavía debe ser un escándalo sui generis sin irreligiosidad ni otras formas de perversión del instinto social. En cuanto a La Vorágine el género de vaguedad panteísta de la selva es parecido al de Conrad en sus novelas del mar y todos recuerdan que Conrad se vendió muy poco cuando se publicaron hace treinta años sus obras completas. Así y todo esas dos novelas se tradujeron, pero su falta de éxito es para los editores un argumento más en contra de la novela iberoamericana. En fin, que las buenas novelas indígenas que no son verdaderamente populares en México, Centroamérica, Chile o Venezuela porque no hay masas literariamente incorporadas tampoco pueden serlo en América donde hay grandes masas incorporadas y mal educadas literariamente.

Entre los últimos libros que he leído me ha impresionado bastante el de Manuel Rojas Hijo de Ladrón. No sé qué crítica habrá tenido en su país. La verdad es que la crítica en casi todos los países iberoamericanos es de una simplicidad de reacciones sorprendente. Muy rara vez un crítico se toma la pena de formarse una opinión. Prefiere seguir la del grupo o camarilla cuyo aliento recibe. Piensan casi todos en lo que se lleva y hay en ellos un santo horror a quedarse atrasado en relación con la moda. Cuando el que corre detrás del último grito es poeta o novelista y tiene talento como Rubén 
o Güiraldes hace algo de veras notable. Toman la esencia de las formas en uso y las incorporan y funden con sus propias motivaciones. El resultado puede ser espléndido. Pero en la crítica es diferente. La asimilación de los clichés, las frases hechas y las síntesis de las opiniones al uso en Europa producen a veces un verdadero galimatías. Se mezclan citas y alusiones tan dispares como Newton, el complejo de Edipo, Pitágoras, Charles Chaplin, San Agustín, Kafka, el conde Keyserling y Cocteau para autorizar por ejemplo el análisis del carácter sentimental de la protagonista. $Y$ no son siempre los críticos iberoamericanos, porque el que nos sugiere estas líneas es un español que todavía vende el averiado artículo vanguardista en Buenos Aires. $\mathrm{Ni}$ son todos los críticos porque hay plumas sagaces y delicadas como la de Alfonso Reyes, aunque las ninfas helenas que importó en México y distribuyó por los lagos y ríos fueron implacablemente devoradas por Tláloc, dios de las aguas.

El último ejemplo como digo de novela rapsódica es el de $\mathrm{Ma-}$ nuel Rojas. Antes había leído yo otra narración del mismo autor: Lanchas en la Bahia que el prologuista Alone en un exquisito prefacio con el que no estoy de acuerdo compara con los cuentos de Maupassant. Creo que Lanchas en la Bahia está muy lejos de ese autor francés y tiene, en cambio, un eco vivo y directo de autores más modernos en quienes prima la descripción y no la narración y el estilo y no la estructura. Cuando se publicó Lanchas en la Bahía gozaba de cierta boga en Francia y en algunos países iberoamericanos el autor galo-rumano Panait Istrati. Es con él con quien ese librito primigenio de Manuel Rojas está emparentado, aunque tiene bastante vigor para tenerse en pie por sí mismo.

Si Lanchas en la Bahía en una pequeña narración maestra, en mi opinión la novela de Rojas que despierta el interés de las obras verdaderamente originales es Hijo de Ladrón. Lo mismo que en la anterior sus virtudes son de estilo y no de estructura y presentan una actitud ante la realidad que no tiene precedentes en nuestra literatura. En su conjunto promueve el mismo curioso fenómeno de las novelas de Güiraldes y Gallegos: la lisis lírica en la que se nos ofrece algún matiz difícilménte ponderable $y$, sin embargo, extrañamente revelador de lo que es la atmósfera local o territorial o si se quiere nacional de la patria del autor. Lo que Güiraldes es a la pampa y Rivera a la selva - las dos opuestas a la ciudad y pasivas e 
indomeñables - es Gallegos a la lucha callada de la selva con la urbe y Azuela a la lucha sangrienta de la paramera con la colonia (colonia en el sentido latino de tierra cultivada). Así como Güiraldes y Rivera se declaran vencidos por la grandeza de un misterio natural más fuerte que los recursos de su imaginación; Gallegos y Azuela tratan de crear el conflicto y de presentar los dos aspectos de la lucha entre el hombre natural y el social y de intervenir en esa contienda aunque sin olvidar un instante que serán vencidos también y que la belleza estará en la esterilidad de un combate cuyas circunstancias secretas no llegan a hacerse presentes sino por alusiones, como lo inefable lírico sólo se hace perceptible por la indirecta alusión de la imagen. Así, Güiraldes es la Argentina, como Rivera es Colombia y Azuela es México y Gallegos es Venezuela. En Manuel Rojas hay también la alusión poética y la llamada a esa vaguedad rapsódica où lindécis au précis se joint según Verlaine. Con ella se nos muestra no la abrumadora grandeza de un paisaje natural, ni el alma de un territorio, ni la lucha del hombre natural con el hombre social sino al ciudadano frustrado y perdido en los laberintos periféricos de la sociedad. Al hombre que lleva dentro las más complejas contradicciones del mestizaje. Al ciudadano del suburbio, sin papeles de identidad.

Para mí que no conozco Chile sino a través de referencias y lecturas, este país ha sido siempre entre los de América el que tiene una sociedad más civil, más comprometida con la urbe y más afectada, si se me permite decirlo así, por las ordenanzas municipales. Tengo la impresión -y permítaseme expresarla de un modo chocantemente aproximado- de que todo su campo, incluso el más bravio, es suburbio. Tal vez porque la montaña es inhabitable y el mar también, la población vive en la estrecha faja intermedia y su actitud natural es elusiva como la del que anda, vive y mira de medio lado. Para vivir entre los hombres no es bueno tener siempre el océano debajo y la montaña encima y al tratar de eludirlos (eludir su abrumadora presencia) el chileno no tiene más remedio que vivir y ver sesgado. Los chilenos que he conocido en Madrid, París o New York - y también en Berlín, en Lisboa y en Moscú, porque hay chilenos en todos los rincones del mundoeran siempre hombres de ciudad. Armando Donoso, Neruda, María Monvel, Enrique Espinoza, María Luisa Bombal, el mismo ex pre- 
sidente Alessandri, el antiguo embajador Rodríguez Mendoza - viejo amigo de Rubén-y tantos otros eran todos hombres de ciudad. En sus ciudades había barrios nobles y hasta acrópolis - de una de ellas parece haber salido Torres-Rioseco, sólido y jovial- pero cuando esos chilenos querían mostrarse campesinos o marineros eran hombres no de mar ni de montaña sino de valle semiurbanizado, es decir - como dije antes - de suburbio. En los argentinos se ve a menudo el campo. Incluso en viejos patricios como Marcelo $\mathrm{T}$. de Alvear - a quien conocí en Madrid en los años 1920 - se podía ver el punto de partida campesino y agreste.

Pues bien, el héroe de Manuel Rojas es el suburbio chileno. Conozco un distinguido doctor chileno que vive en la misma ciudad que yo - don Lautaro Vergara- y que además de sus talentos profesionales cultiva el deporte más antiguo de la humanidad: la caza de animales salvajes con arco y flecha. $\mathrm{Ha}$ sido mi maestro en ese ejercicio y puede ser maestro de cualquiera como atestiguan los trofeos de los que está llena su casa, incluídas las pieles y las cabezas disecadas de grandes osos y tigres. El mismo se precia de su origen mixto araucano y vasco. A pesar de todas esas circunstancias es un hombre de ciudad al modo chileno, es decir, un hombre con su cortesía de extramuros y de arrabal. (No un campesino ni un marinero, ni un montañés, ni un pastor.) $\mathrm{Y}$ al hablar de "extramuros" y de arrabal me refiero como el lector habrá imaginado a la ciudad nueva. En una ciudad en desarrollo y crecimiento todo es suburbio.

E1 héroe de Manuel Rojas es el suburbio chileno. Sería absurdo pensar que si el argentino de Güiraldes es el gran señor pampero y. el venezolano de Gallegos el mestizo con la crueldad mágica e inocente heredada por un lado de las savias indias y por otro de la muda crueldad de los rebeldes de Lope de Aguirre; y si el mexicano es el charro con el cinturón de balas que describe Azuela, sería absurdo pensar que el chileno es el "hijo de ladrón" de Manuel Rojas. Es tan anómalo y fuera de congruencia que la misma excusa y prevención contra el malentendido resulta ridícula.

No es el héroe de Rojas un ladrón, sino un hijo de ladrón y 1a familia entera es más convincente en su inocencia que los héroes de Gide en su perversidad o los de Malraux en su nervioso y acuciador idealismo. El hijo del ladrón nos plantea su propia inocen- 
cia de mil maneras realmente suasorias. Anteponer la paternidad a la condición viciosa del delincuente es ya ponernos por delante una compensación: el ladrón antes que ladrón es padre. Aunque el ser padre a secas y sin calificación no puede ser una virtud, es una cualidad natural que despierta simpatía. Pero además como padre es de una falta de originalidad - - es decir, de peculiaridadrealmente virtuosa. $\mathrm{Y}$ dentro del marco familiar el ladrón es un hombre responsable a su manera y con sentido del hogar. Tal vez no acepta otra institución social que la familia. El juez dirá lo que quiera, pero ¿ no es la familia, incluso esa familia, la base de la sociedad moderna? En todo caso cualquier reflexión de orden psicológico, moral, social, no hará sino despistar al lector y los valores de esa novela como los de los libros citados antes rebasan el nivel de las consideraciones positivas, es decir, útiles desde el punto de vista civil, urbano -o suburbano- en el sentido ordinario. Igual que las grandes novelas anteriores Hijo de Ladrón obtiene una atmósfera esencial por subordinación de todos los demás elementos incluído el de los juicios morales. En ese sentido es más ambiciosa la tarea de Rojas que la de Güiraldes, Rivera y Azuela. La pampa tenía ya una tradición literaria gloriosa y lo mismo sucede con la selva y con la revuelta armada de los desiertos mexicanos. Pero la ciudad chilena y tal vez la suramericana es virgen, más virgen en muchos sentidos que la pampa y la selva. $Y$ definir el suburbio usando del realismo y el naturalismo no como fines sino como instrumentos para obtener esa nebulosa de tonos fríos (fríos como cualquier otro producto de la mera sensibilidad intelectual) que es Hijo de Ladrón es una empresa de gigante. ¿Cómo se define esa ciudadanía del suburbio chileno? Sería fácil y probablemente inexacto acumular virtudes convencionales que dependerían sólo de la inclinación selectiva del autor y que no harían sino añadir términos nuevos a la confusión y al caos. Rojas obtiene esa definición por la determinación de su ausencia, de la ausencia de esa ciudadanía. Señala con alusiones de naturaleza metafórica la imposibilidad e inexistencia de un orden. Es decir, que nos muestra no más el lugar que la ausencia de esa ciudadanía ideal deja vacante en los espacios del gran suburbio. Algunos escritores han hablado de las culturas bastardas de América. En realidad todas las culturas, menos la hindú y la china pueden considerarse bastardas y todos los pue- 
blos han tratado de desmentir en su literatura esa bastardía. La literatura es el documento de legitimización de una cultura.

Pero si todas las literaturas han tratado de deslindar y discriminar los elementos del caos inicial para encontrar un acento, una voz, un símbolo generalizador y levantar su mito - el mito quijotesco español, el mito burgués francés, el mito insular británico, el del idealismo germano, el del materialismo yanqui, el del gigantismo místico ruso- tal vez la manera de superar el caos americano hispanoparlante - ese caos está en la ciudad y no en la selva ni en el desierto- es aceptarlo e iluminarlo sin piedad ni farisaícos pudores. La confesión religiosa o freudiana, útil para el individuo no será tampoco inútil para las sociedades. Pero esta confesión sería de una eficacia dudosa y tal vez de un carácter sórdido y contraproducente si no estuviera autorizada por el talento literario y por la poesía. La urbe nueva de Rojas tiene una ausencia de reactivos morales nueva también. Ahí está esa ausencia. El que sepa leer que lea y el que pueda entender...

Pero la verdad es que en el libro de Manuel Rojas no hay mucho que entender. Como en las otras novelas iberoamericanas y en la poesía moderna en Hijo de Ladrón el autor no se dirige sólo a la inteligencia. Es decir, no se dirige explícitamente a la inteligencia. ¿Cuáles podrían ser las reacciones de la usual razón ante las escenas que el libro nos ofrece y que caen siempre fuera de las situaciones previstas por la experiencia de la vida incluso por la experiencia de la vida novelesca? La razón, el juicio moral, el sentimiento discursivo y polémico, la argumentación lógica se inhiben a menudo. Queda prendida, sin embargo, nuestra atención y tenemos una curiosidad y una emoción que no dependen de nuestra identificación sentimental o intelectual con el héroe ni con el antihéroe -todos son héroes y antihéroes al mismo tiempo- sino de una extrañeza que desde las páginas del libro revierte sobre nosotros mismos y que consiste en el descubrimiento de una inhumanidad latente que está en todas partes y que casi nadie se atreve a confesar. Es la emoción de nuestra insolidaridad humana patente y viva. ¿Nos acusa Rojas de esa falta de sintonía o de simpatía? No. ¿ Para qué? ¿ No somos nosotros, cada uno de nosotros, la víctima de nuestra propia insolidaridad? 
Ortega y Gasset que ya no está de moda, pero que ahora es cuando deja ver mejor -al perder la novedosidad y la superficial asistencia de los trivios - su fuerza y su agudeza, habló un día de la deshumanización del arte. Algunos se escandalizaron. Hace poco se ha publicado ese ensayo en América y las reacciones han sido parecidas. ¿Deshumanización del arte? La primera impresión es incómoda, pero ¿ cómo vamos a extrañarnos de esas palabras de Ortega y Gasset cuando vemos en todas las manifestaciones de la vida la tendencia del hombre a su propia deshumanización? Ser humano es, ante todo, respetarse en el respeto a los demás hombres. Y cuando vemos hasta dónde ha llegado esa desestimación de sí en sí mismo y en los otros (crímenes de masas, atonía moral de los regímenes totalitarios, campos de concentración de Dachau, de Vorkuta, asesinatos y paseos sin regreso en España) ¿por qué vamos a asombrarnos de que una mente lúcida nos hable de ese mismo fenómeno de desinterés de lo humano en el arte de Picasso, de Apollinaire o de Valle Inclán? ¿Deshumanización del hombre? A1 menos en el arte hay una excusa más o menos legítima: la belleza formal. En todo caso ahí está el hecho: la atonía y la indiferencia por nuestra propia humanidad. La atrofia de ese nexo ganglionar que nos une - al margen de la razón- a los intereses comunes de la especie. En esa zona indeterminable de nttestro inconsciente no gregario sino sencillamente solidario que nos obliga a ser hombres antes que ciudadanos, ahí es donde Hijo de Ladrón proyecta sus luces frías.

Habla Freud de la esquizofrenia del artista, que no es una tara sino una especie de condicionamiento profesional. Es esa también una observación que nos ayuda a entender algunas formas de la literatura y el arte modernos. Así como en la pintura, la escultura y la música de hoy, el artista muestra sus secretos sin cuidarse de la elocuencia externa de su obra sino de la originalidad a vecess áspera de los estímulos interiores en la literatura; el novelista con su personalidad escindida no sólo trata de mostrarnos su problema de desintegración penosa sino que nos empuja a cada uno de nosotros, lectores, a ver también el nuestro. Ahí es donde la hombría primaria separada de la razón moral - el bosquimano y el hombre social que todos llevamos dentro- nos pone a la vista y ofrece a nuestro análisis esa falta de respuesta que hay en la mayoría de los hombres para la pregunta del dolor ajeno. De paso nos dice también 
cómo ese dolor impregna todas las formas sensibles de la realidad que nos rodea.

El poeta Rojas pone esa realidad delante y la anima. Eso es todo, ni más ni menos. No aspira a suscitar la protesta ni el clamor retórico sino la sorpresa, la perplejidad y el dudoso y tímido placer de una alusión a formas de armonía basadas - rara tortura de la belleza- en una sobrentendida crueldad. En tna potencial crueldad que está también latente en nosotros y que en un momento dado puede informar y conducir nuestra vida y la de los otros. De nada de esto habla Rojas concretamente y si hablara no haría sino una argumentación que seguramente no conmovería más que la superficie de nuestra conciencia. Pero gracias a una de esas argucias nobles, que el artista improvisa a tono con el de su verdad, nos pone delante su suburbio para que de ese caos iltuminado extraigamos nosotros nuestras evidencias. ¿Utiles? ¿Inútiles? iBah!, el artista sabe que nunca seguiremos otra norma que aquella que creamos descubrir nosotros mismos. $Y$ sabe también que entre un descubrimiento lógico y otro voluptuoso y placentero será más convincente este último. He aquí, pues, la esencialidad inefable que actúa en esta novela como en Doña Bárbara y Don Segundo Sombra sobre nosotros como un argumento eficaz. $\mathrm{Y}$ he aquí que lo que podría ser estéril lección, es decir, sugerencia de una verdad moral que por obvia olvidaríamos despierta un repertorio de emociones que no nos abandonará fácilmente. En ellas queda disuelta la noción - por ausencia - de una ciudad no existente. Sobre esas y otras emociones cristalizará la ciudad nueva un día. Tal vez esa es la noción de la ciudad del futuro por la que con nuestra voluntad o con nuestros presentimientos y sueños todos trabajamos expresamente o sin querer.

Ramón J. Sender, Universidad de New Mexico, Albuquerque, N. M. 
